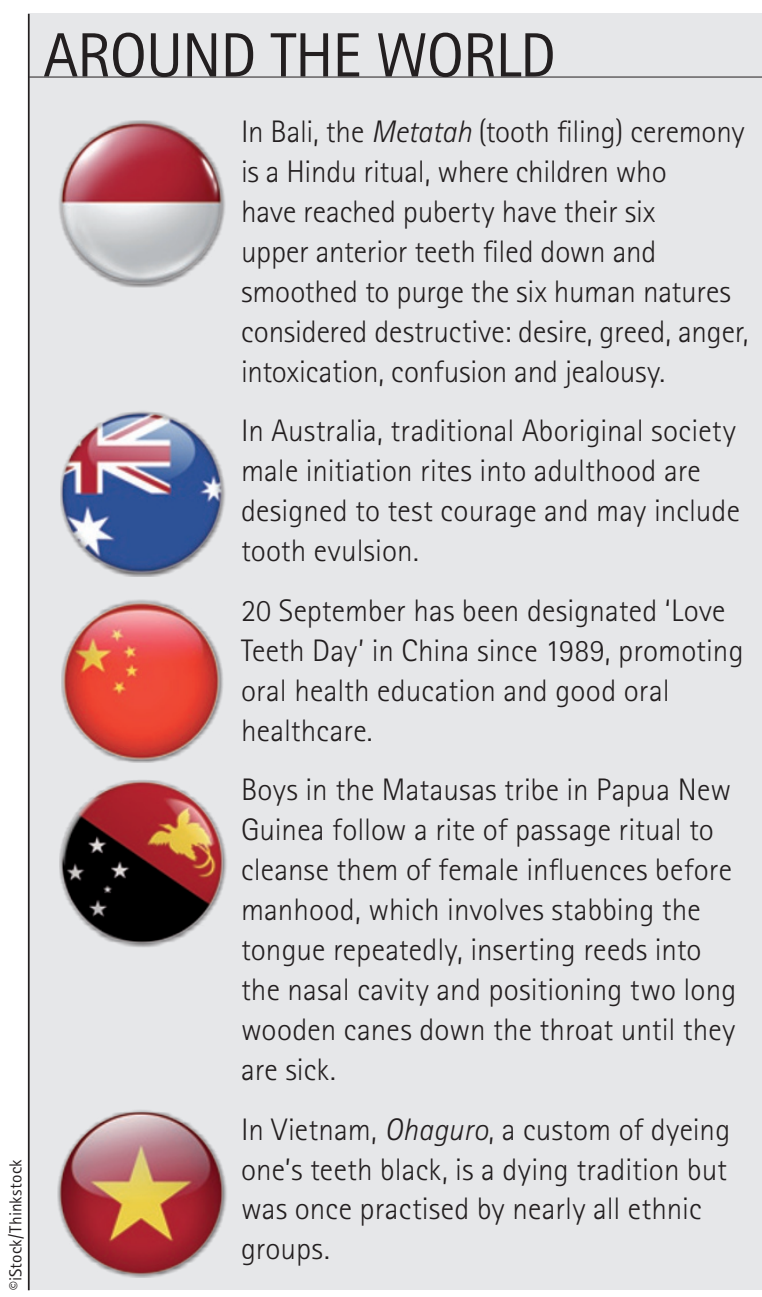

\title{
COULD BEER DREGS HELP FIGHT DENTAL DISEASES?
}

New research into the polyphenolic compounds found in hop bracts, the part of the leaves not used in beer brewing, has successfully identified the anticaries and antiperiodontitis properties that the leaf exhibits. ${ }^{1}$

Tanaka et al. have previously documented the beneficial antioxidants found in bracts of hops that could be used in the fight against dental diseases, ${ }^{2,3}$ but until now the structural composition of these potentially valuable polyphenolic compounds had not been analysed. Using a novel sequential chromatographic technique, the structures of 39 compounds were expounded from a hop bract extract. Of these, substances were found to inhibit cellular adherence of Steptococcus mutans, cariogenic bacteria, and the effects of Porphyromonas gingivalis, a major periodontal pathogen. Tanaka told the $B D J$ : 'This study is very significant because it will be clear what substances in hop bracts prevent dental diseases. If the substances that prevent dental diseases are elucidated, concentrated mixtures of the substances might be produced by purification.'

Hop bracts are currently an unused waste product of beer brewing and this research could act as a driving force behind the industrial use of hop bracts in the prevention of dental diseases, as Tanaka adds: 'In the near future, toothpaste, gum, juice or tea containing the extract of the leaves will be developed [through] a simpler method of producing hop bract extract.'

1. Tanaka Y, Yanagida A, Komeya S et al. Comprehensive separation and structural analyses of polyphenols and related compounds from bracts of hops (Humulus lupulus L.). J Agric Food Chem 2014; 62: 2198-2206.

2. Shinada, $K$, Tagashira M, Watanabe $H$ et al. Hop bract polyphenols reduced three-day dental plaque regrowth. J Dent Res 2007; 86: 848-851

3. Yaegaki K, Tanaka T, Sato T et al. Hop bract polyphenols reduced three-day dental plaque regrowth. J Dent Res 2007; 86: 848-851.

BY LAURA PACEY

\section{VIKING TEETH OFFER INSIGHT INTO CULTURAL STATUS}

A mong the weaponry, jewellery and other artefacts displayed in the new British Museum exhibition Vikings: life and legend, rests a jawbone with filed teeth: an example of dental modification in a culture that flourished over 1,000 years ago.

There has been great speculation as to the reasons behind this Viking dental oddity since 2005, with the furst discovery of deliberate dental modification in archaeological human skeletal material from Europe. ${ }^{1}$ The manmade horizontally filed furrows on the upper part of the crowns found in 24 men dating between 800-1050 AD were evidently made by a skilled hand, but whether for decoration or identification of a certain group remains unclear.

The Viking burial pit discovered at the Weymouth Relief Road in Dorset in 2009 provided further evidence of tooth filing, but this time within Britain rather than Scandinavia. The burial pit contained around 50 beheaded individuals with bodies thrown into a mass grave and heads placed carefully in a collection at one edge. ${ }^{2}$ One individual displayed deliberately-filed teeth, which may have been a symbol of his status. The Vikings, known for their fearsome image, may have filed their teeth to appear more menacing. Gareth Williams, curator of the

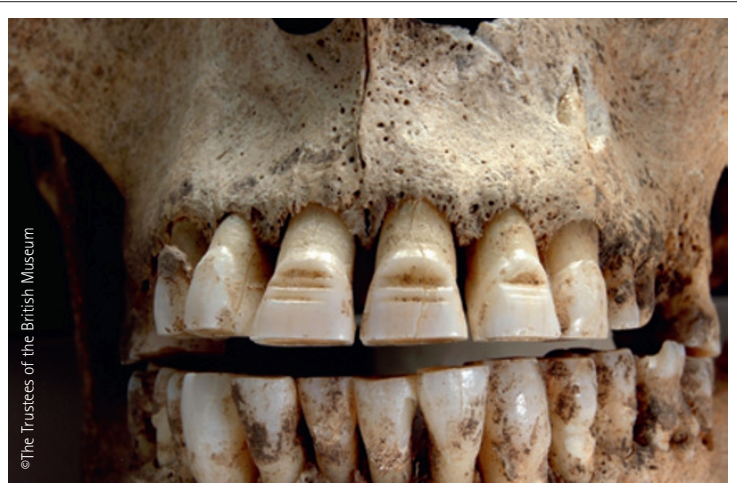

British Museum exhibition that will feature the burial, noted: '[it is] one of the most dramatic Viking finds of recent years." ${ }^{4}$ The filed teeth are on display at the British Museum until 22 June 2014.

1. Arcini $C$. The Vikings bare their filed teeth. Am J Phys Anthropol 2005; 128: 727-733.

2. Loe L, Boyle A, Webb H, Score D. 'Given to the ground': a Viking age mass grave on Ridgeway Hill, Weymouth. Oxford: Oxford Archaeology, 2014.

3. Oxford Archaeology. Dorset Viking age mass burial publication. Past Horizons 2014.

BY LAURA PACEY 